IUCr]

ISSN 2052-2525

BIOLOGY|MEDICINE

Received 3 July 2017

Accepted 6 December 2017

Edited by Z.-J. Liu, Chinese Academy of Sciences, China

Keywords: nitric oxide; peroxiredoxins; crystal structure; Vibrio vulnificus; protein structure; X-ray crystallography.

PDB references: reduced $\operatorname{Prx} 3(\mathrm{C} 48 \mathrm{D} / \mathrm{C} 73 \mathrm{~S})$, 5k1g; oxidized Prx3 (C73S), 5k2i; $\mathrm{H}_{2} \mathrm{O}_{2}$-bound $\operatorname{Prx3}$ (C48D/C73S), 5k2j

Supporting information: this article has supporting information at www.iucrj.org

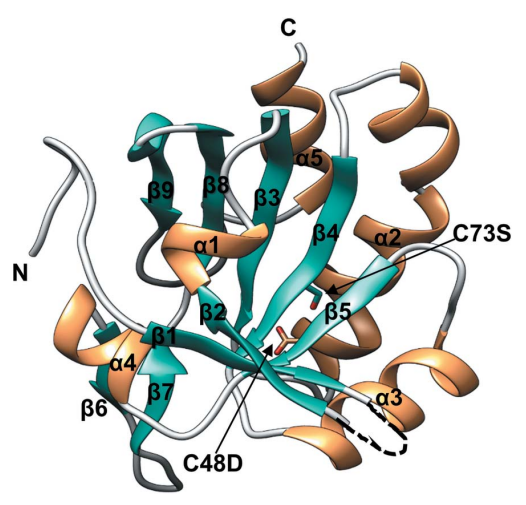

OPEN $\odot$ ACCESS

\section{Crystal structure of peroxiredoxin 3 from Vibrio vulnificus and its implications for scavenging peroxides and nitric oxide}

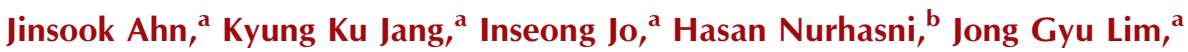 \\ Jin-Wook Yoo, ${ }^{b}$ Sang Ho Choi ${ }^{\mathrm{a} *}$ and Nam-Chul $\mathrm{Ha}^{\mathrm{a} *}$
}

\footnotetext{
a Department of Agricultural Biotechnology, Seoul National University, 1 Gwanak-ro, Seoul 08826, Republic of Korea, and ${ }^{\mathbf{b} C o l l e g e}$ of Pharmacy, Pusan National University, Busandaehak-ro, Pusan 46241, Republic of Korea.

*Correspondence e-mail: choish@snu.ac.kr, hanc210@snu.ac.kr
}

Peroxiredoxins (Prxs) are ubiquitous cysteine-based peroxidase enzymes. Recently, a new type of Prx, $V v \operatorname{Prx} 3$, was identified in the pathogenic bacterium Vibrio vulnificus as being important for survival in macrophages. It employs only one catalytic cysteine residue to decompose peroxides. Here, crystal structures of $V v \operatorname{Prx} 3$ representing its reduced and oxidized states have been determined, together with an $\mathrm{H}_{2} \mathrm{O}_{2}$-bound structure, at high resolution. The crystal structure representing the reduced Prx 3 showed a typical dimeric interface, called the A-type interface. However, $V v \operatorname{Prx} 3$ forms an oligomeric interface mediated by a disulfide bond between two catalytic cysteine residues from two adjacent dimers, which differs from the doughnut-like oligomers that appear in most Prxs. Subsequent biochemical studies showed that this disulfide bond was induced by treatment with nitric oxide (NO) as well as with peroxides. Consistently, NO treatment induced expression of the prx3 gene in $V$. vulnificus, and $V v \operatorname{Prx} 3$ was crucial for the survival of bacteria in the presence of NO. Taken together, the function and mechanism of $V v \operatorname{Prx} 3$ in scavenging peroxides and NO stress via oligomerization are proposed. These findings contribute to the understanding of the diverse functions of Prxs during pathogenic processes at the molecular level.

\section{Introduction}

Most organisms have evolved efficient defence systems that rapidly detoxify potentially damaging reactive oxygen species (ROS). ROS are generated during aerobic respiration and in the host immune system (Temple et al., 2005; Cabiscol et al., 2000; Halliwell, 2006). Peroxiredoxins (Prxs) represent a superfamily of thiol-specific antioxidant peroxidases that use an invariant cysteine residue(s) (Engelman et al., 2013). They are highly conserved throughout evolution and are ubiquitously found from humans to bacteria. Prxs decompose peroxides such as hydrogen peroxide $\left(\mathrm{H}_{2} \mathrm{O}_{2}\right)$ and alkyl hydroperoxides in the cytosol (Rhee et al., 2005; Wood et al., 2003; Engelman et al., 2013). Recent research has reported that Prxs are also involved in the detoxification of reactive nitrogen species (RNS), which are produced in phagocytes as a key component for killing invading bacteria (Wong et al., 2002; Bryk et al., 2000). Prxs have been found to detoxify peroxinitrite $\left(\mathrm{ONOO}^{-}\right)$and nitrosylated thiols (Fang, 2004; Beckman \& Koppenol, 1996; Pfeiffer et al., 1997).

Prxs have a peroxidatic cysteine $\left(C_{P}\right)$ that reacts with peroxides in the first step of catalysis. The $\mathrm{C}_{\mathrm{P}}$ is oxidized to cysteine sulfenic acid $\left(\mathrm{C}_{\mathrm{P}}-\mathrm{SOH}\right)$ by attacking the $\mathrm{O}-\mathrm{O}$ bond of peroxides during the peroxidase reaction, resulting in the decomposition of peroxides (Wood et al., 2003). The $\mathrm{C}_{\mathrm{P}}-\mathrm{SOH}$ is then reduced during the resolution step, which is needed to 
recycle the protein. Depending on the resolution step, Prxs are classified into three types, referred to as typical 2-Cys, atypical 2-Cys and 1-Cys Prxs (Hall et al., 2011). Both types of 2-Cys Prx have an additional conserved cysteine residue called the resolving cysteine $\left(C_{R}\right)$, which forms a stable intermolecular or intramolecular disulfide bond with the $\mathrm{C}_{\mathrm{P}}-\mathrm{SOH}$. While $\mathrm{C}_{\mathrm{R}}$ is located in a separate subunit in typical 2-Cys Prxs, it is located within the same subunit in atypical 2-Cys Prxs (Seo et al., 2000; Hall et al., 2009). The disulfide bond in 2-Cys Prxs can be broken into two free thiols by cellular reductants (Chae et al., 1999). In contrast, the $\mathrm{C}_{\mathrm{P}}-\mathrm{SOH}$ of 1-Cys Prxs has been implicated to be directly reduced by cellular reductants such as glutaredoxin (Grx) and/or the reduced form of glutathione (GSH) (Noguera-Mazon et al., 2006; Kang et al., 1998; Rhee et al., 2005). In a yeast 1-Cys Prx, the $\mathrm{C}_{\mathrm{P}}-\mathrm{SOH}$ has been proposed to form a disulfide bond with the $\mathrm{C}_{\mathrm{P}}$ residue of another molecule of Prx (Pedrajas et al., 2016).

Although the oligomeric states of Prxs differ depending on the type of Prx, most oligomeric Prxs are formed via two major distinct interfaces: B-type and A-type interfaces (Parsonage $e t$ al., 2005). In typical 2-Cys Prxs, dimers are primarily formed via the B-type interface, in which $\mathrm{C}_{\mathrm{P}}$ and $\mathrm{C}_{\mathrm{R}}$ are located in different protomers and disulfide formation between $C_{P}$ and $C_{R}$ is facilitated by peroxides (Echalier et al., 2005). In most 2-Cys Prxs, five dimers are further associated via the A-type interface to form a doughnut-like decamer (Wood et al., 2002; Parsonage et al., 2005). Most atypical 2-Cys Prxs and 1-Cys Prxs exhibit dimeric assembly via the A-type interface (Evrard et al., 2004; Li et al., 2005). Exceptionally, a non-A and non-B oligomeric interface between $C_{P}$ and $C_{R}$ was observed in human Prx5 (HsPrx5), which belongs to the atypical 2-Cys Prx family (Smeets et al., 2008) and showed redox-dependent structural changes in the $\mathrm{C}_{\mathrm{P}}$-containing region. The structural change was distinguished from that in some typical 2-Cys Prxs (Wood et al., 2003; Parsonage et al., 2005). In the presence of excess peroxides the $\mathrm{C}_{\mathrm{P}}$ can be overoxidized to cysteine sulfinic acid or cysteine sulfonic acid $\left(\mathrm{C}_{\mathrm{P}}-\mathrm{SO}_{2} \mathrm{H}\right.$ or $\mathrm{C}_{\mathrm{P}}-\mathrm{SO}_{3} \mathrm{H}$, respectively). Interestingly, the protomers with overoxidized $\mathrm{C}_{\mathrm{P}}$ exhibit the same conformation as in Prxs in the reduced state (Mizohata et al., 2005; Nakamura et al., 2006).

Vibrio vulnificus is a highly virulent foodborne pathogen that can cause fatal septicaemia (Oliver, 2005; Horseman \& Surani, 2011). The bacterium has three different types of Prx: Prx1, Prx2 and Prx3. Prx1 and Prx2 belong to the typical 2-Cys Prx family of proteins and their expression is controlled by the $\mathrm{H}_{2} \mathrm{O}_{2}$-activated transcription factor OxyR (Kim et al., 2014; Jo et al., 2015). V. vulnificus Prx3 (VvPrx3) belongs to the 1-Cys class of Prxs, with one conserved catalytic cysteine (Cys48), and has been shown to be involved in pathogenicity in a mouse model. According to the PeroxiRedoxin Classification Index (PREX) database (http://www.csb.wfu.edu/prex), it belongs to the Prx5 subfamily. $V v \operatorname{Prx} 3$ expression is controlled by IscR, which is activated by oxidative stress and iron starvation (Lim et al., 2014). In this study, we determined crystal structures of $V \nu \operatorname{Prx} 3$ in two different forms and in complex with $\mathrm{H}_{2} \mathrm{O}_{2}$. Based on the crystal structures, we present a molecular mechanism of 1-Cys Prxs that highlights the oligomer interface containing a disulfide bond between two peroxidatic cysteine residues. More importantly, we examined the expression of prx3 in $V$. vulnificus induced by nitric oxide gas (NO); consistently, $V \nu \operatorname{Prx} 3$ reacts with nitric oxide.

\section{Experimental procedures}

\subsection{Plasmid construction}

The $V v \operatorname{Prx} 3(\mathrm{C} 48 \mathrm{D} / \mathrm{C} 73 \mathrm{~S})$ and $V v \operatorname{Prx} 3(\mathrm{C} 73 \mathrm{~S})$ genes of $V$. vulnificus were cloned into the pET-21c vector (Invitrogen). To clone the $V v \operatorname{Prx} 3$ gene for the expression of $V v \operatorname{Prx} 3$ (C73S), two primers (forward, 5'-GGTCATATGATCGCTC AAGGCCAAACTTTACC-3'; reverse, 5'-CCTCTCGAGCG CGGCAAGAATCGTTTCAGC-3') were designed, which contained NdeI and XhoI sites (underlined), respectively. Site-directed mutagenesis was performed in two subsequent PCR reactions for the expression of $V v \operatorname{Prx} 3$ (C48D/C73S) (Ho et al., 1989). The PCR products and pET-21c plasmid were digested by NdeI and XhoI, and the digested products were ligated with DNA ligase. The ligation products were transformed into Escherichia coli C43 (DE3) cells by heat shock. Finally, the recombinant plasmid was confirmed by DNA sequencing.

\subsection{Expression and purification of recombinant proteins}

Recombinant proteins were expressed in LB medium containing $50 \mu \mathrm{g} \mathrm{ml}^{-1}$ ampicillin, with growth at $310 \mathrm{~K}$ to an $\mathrm{OD}_{600}$ of 0.5 . Samples were induced with $0.5 \mathrm{~m} M$ isopropyl $\beta$-D-1-thiogalactopyranoside (IPTG) for $6 \mathrm{~h}$ at $303 \mathrm{~K}$. The cells were harvested and resuspended in lysis buffer consisting of $20 \mathrm{~m} M$ Tris- $\mathrm{HCl} \mathrm{pH} 8.0,0.15 M \mathrm{NaCl}, 2 \mathrm{~m} M \beta$-mercaptoethanol. After disrupting the cells with a French press, the cell debris was removed by centrifugation. The supernatant was loaded onto Ni-NTA affinity resin (Qiagen, The Netherlands) that had been pre-incubated with lysis buffer. The target protein was eluted with lysis buffer supplemented with $250 \mathrm{~m} M$ imidazole. Eluted recombinant proteins were diluted threefold with $20 \mathrm{~m} M$ Tris- $\mathrm{HCl} \mathrm{pH} 8.0$ buffer containing $2 \mathrm{~m} M \beta$-mercaptoethanol and loaded onto a HiTrap Q column (GE Healthcare, USA). A linear gradient of increasing $\mathrm{NaCl}$ concentration was applied to the column. The fractions containing the protein were pooled, concentrated and applied onto a size-exclusion chromatography column (HiLoad 16/600 Superdex 200 pg, GE Healthcare) pre-equilibrated with lysis buffer. The final protein samples were concentrated to $20 \mathrm{mg} \mathrm{ml}^{-1}$ using a centrifugal filter concentration device (Millipore; $10 \mathrm{kDa}$ cutoff) and stored frozen at $193 \mathrm{~K}$ until use.

\subsection{Crystallization, structure determination and refinement}

Crystallization was performed at $287 \mathrm{~K}$ using the hangingdrop vapour-diffusion method. Crystals of Prx3 (C48D/C73S) were obtained using a precipitant solution consisting of $0.2 \mathrm{M}$ $\mathrm{NaCl}, 0.8 M$ sodium citrate, $0.1 M$ Tris- $\mathrm{HCl} \mathrm{pH}$ 6.5. The structure of reduced Prx3 (C48D/C73S) was determined using the molecular-replacement method with MOLREP in the CCP4 package (Winn et al., 2011) using a putative thioredoxin 
reductase from Burkholderia cenocepacia (PDB entry 4f82; Seattle Structural Genomics Center for Infectious Disease, unpublished work) as a search model. The crystal of Prx3 (C48D/C73S) obtained under reduced conditions [reduced Prx3 (C48D/C73S)] belonged to space group $P 3_{2} 21$, with unit-cell parameters $a=73.9, b=73.9$, $c=62.3 \AA$ and one protein molecule in the asymmetric unit (Table 1). After 5 d, Prx3 (C73S) crystals appeared with a precipitant solution consisting of $0.1 M$ sodium citrate $\mathrm{pH} 5.5,0.2 \mathrm{M}$ ammonium acetate, 22\%(w/v) PEG 4000. Crystals were exchanged into the appropriate mother liquor containing $20 \%(v / v)$ glycerol, mounted on cryoloops and flash-cooled in a liquidnitrogen stream at $100 \mathrm{~K}$. X-ray diffraction data sets were collected on beamline 5C at the Pohang Accelerator Laboratory and were processed with the $H K L-2000$ package (Otwinowski \& Minor, 1997). The crystal of Prx3 (C73S) obtained under oxidized conditions [oxidized Prx3 (C73S)] belonged to space group $P 2_{1} 2_{1} 2_{1}$, with unit-cell parameters $a=39.5, b=57.4, c=124 \AA$ and two protein molecules in the asymmetric unit (Table 1). The oxidized Prx3 (C73S) crystals were flash-cooled using a crystallization solution with the same cryoprotectant as used for the reduced Prx3 (C48D/C73S) crystals in a nitrogen stream at $100 \mathrm{~K}$. The initial model of oxidized Prx3 (C73S) was determined by molecular replacement using the structure of reduced Prx3 (C48D/C73S) as a model and was refined at $2.0 \AA$ resolution (Table 1 ). The final structure of oxidized Prx3 (C73S) was refined at $1.48 \AA$ resolution using PHENIX (Afonine et al., 2012). To obtain

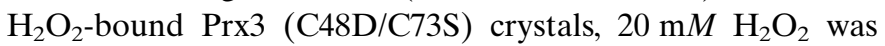
added to the reservoir solution and $500 \mu M \mathrm{H}_{2} \mathrm{O}_{2}$ was added to the hanging-drop solution containing the crystals. After $10 \mathrm{~d}$, the $\mathrm{H}_{2} \mathrm{O}_{2}$-bound Prx3 (C48D/C73S) crystals were flashcooled using the same cryoprotectant as used for the reduced Prx3 (C48D/C73S) crystals in a nitrogen stream at $100 \mathrm{~K}$. The crystals belonged to space group $P 1$, with unit-cell parameters $a=75.08, b=97.72, c=97.49 \AA$ and 12 protein molecules in the asymmetric unit. Statistics regarding data collection and processing are presented in Table 1.

\subsection{Oxidation of $V v \operatorname{Prx} 3$ by $\mathrm{H}_{2} \mathrm{O}_{2}$ or $\mathrm{NO}$}

To prepare the reduced $V v \operatorname{Prx} 3$ (C73S) protein, $10 \mathrm{~m} M$ DTT was added to the purified $V v \operatorname{Prx} 3(\mathrm{C} 73 \mathrm{~S})$ protein and was then removed using a HiPrep 26/10 Desalting column (GE Healthcare, USA) pre-equilibrated with $20 \mathrm{mM}$ Tris- $\mathrm{HCl} \mathrm{pH}$ 8.0 buffer containing $150 \mathrm{~m} M \mathrm{NaCl}$. The reduced $V v \operatorname{Prx} 3$ (C73S) mutant protein was reacted with various concentra- tions of $\mathrm{H}_{2} \mathrm{O}_{2}$ or tertiary butyl hydrogen peroxide $(t-\mathrm{BOOH})$ for $30 \mathrm{~min}$ at $298 \mathrm{~K}$ in $1 \mathrm{ml} 20 \mathrm{mM}$ Tris-HCl buffer $\mathrm{pH} 8.0$ containing $150 \mathrm{~m} M \mathrm{NaCl}$. The reaction mixture was treated with iodoacetamide (IAA) to stop the reaction and subjected to SDS-PAGE under nonreducing or reducing conditions. To analyze Prx3 oxidation during the time course, samples were treated with $50 \mu M \mathrm{H}_{2} \mathrm{O}_{2}$ for $0-60 \mathrm{~s}$ and the reaction was quenched with $10 \mathrm{~m} M N$-ethylmaleimide (NEM). For reaction with $\mathrm{NO}$, reduced $V v \operatorname{Prx} 3(\mathrm{C} 73 \mathrm{~S})$ protein $(10 \mathrm{nmol})$ was treated with $1 \mathrm{mg}$ NO-releasing PLGA-PEI nanoparticles (NO/PPNPs) in $10 \mathrm{ml}$ reaction mixture in $20 \mathrm{~m} M$ Tris $\mathrm{pH} 7.5$, $150 \mathrm{~m} M \mathrm{NaCl}$. The amount of $\mathrm{NO}$ was calculated based on the release of $3.3 \mathrm{nmol} \mathrm{NO}$ per hour by $1 \mathrm{mg}$ NO/PPNPs (Nurhasni et al., 2015).

\subsection{Competitive kinetics with horseradish peroxidase (HRP)}

To prepare the reduced $V \nu \operatorname{Prx} 3(\mathrm{C} 73 \mathrm{~S})$ protein, the purified protein was treated with $10 \mathrm{~m} M$ DTT for $30 \mathrm{~min}$ at room temperature. After reduction of the protein, residual DTT was removed using a HiPrep 26/10 Desalting (GE Healthcare, USA) column pre-equilibrated with $20 \mathrm{~m} M$ Tris- $\mathrm{HCl} \mathrm{pH} 7.5$ buffer containing $150 \mathrm{mM} \mathrm{NaCl}$. Reaction mixtures containing $5 \mu M$ horseradish peroxidase (HRP; Sigma-Aldrich) and various concentrations $(0-9.15 \mu M)$ of reduced $V v \operatorname{Prx} 3$ (C73S) were treated with $2.5 \mu M \mathrm{H}_{2} \mathrm{O}_{2}$ at room temperature in reaction buffer consisting of $50 \mathrm{~m} M$ sodium phosphate $\mathrm{pH} 7.4$, $150 \mathrm{~m} M \mathrm{NaCl}$. The concentration of HRP was calculated using the absorbance at $403 \mathrm{~nm}\left(\varepsilon_{403}=1.02 \times 10^{5} M^{-1} \mathrm{~cm}^{-1}\right)$ and 
the concentration of $V \nu \operatorname{Prx} 3(\mathrm{C} 73 \mathrm{~S})$ was determined at $280 \mathrm{~nm}$ $\left(\varepsilon_{V v \operatorname{Prx} 3}=8.48 \times 10^{3} \mathrm{M}^{-1} \mathrm{~cm}^{-1}\right)$. The competitive kinetics of $V \nu \operatorname{Prx} 3(\mathrm{C} 73 \mathrm{~S})$ were determined using a previously described procedure (Ogusucu et al., 2007; Winterbourn \& Peskin, 2016; Cox et al., 2009). In brief, the ratio of inhibition of HRP oxidation $[F /(1-F)]$ was measured at $403 \mathrm{~nm}$ with a spectrophotometer using a $10 \mathrm{~mm}$ cuvette. The second-order rate constants $\left(k_{1}\right)$ of $V v \operatorname{Prx} 3(\mathrm{C} 73 \mathrm{~S})$ were determined from the slope of a plot of $[F /(1-F)] k_{\mathrm{HRP}}[\mathrm{HRP}]$ against $[V \nu \operatorname{Prx} 3$ $(\mathrm{C} 73 \mathrm{~S})]\left(k_{\mathrm{HRP}}=1.7 \times 10^{7} \mathrm{M}^{-1} \mathrm{~s}^{-1}\right)$.

\subsection{Gel-filtration chromatography}

A Superose 6 HR 10/30 column coupled to an FPLC instrument (Biologic Duo Flow, Bio-Rad) was equilibrated with $20 \mathrm{~m} M$ Tris- $\mathrm{HCl} \mathrm{pH}$ 8.0, $150 \mathrm{~m} M \mathrm{NaCl}$. Samples were

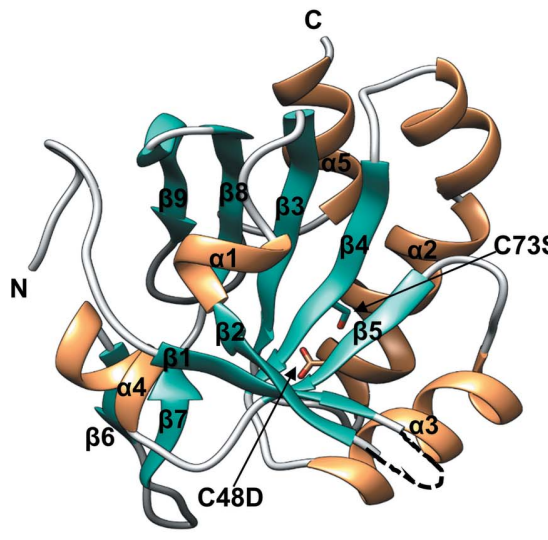

(a)

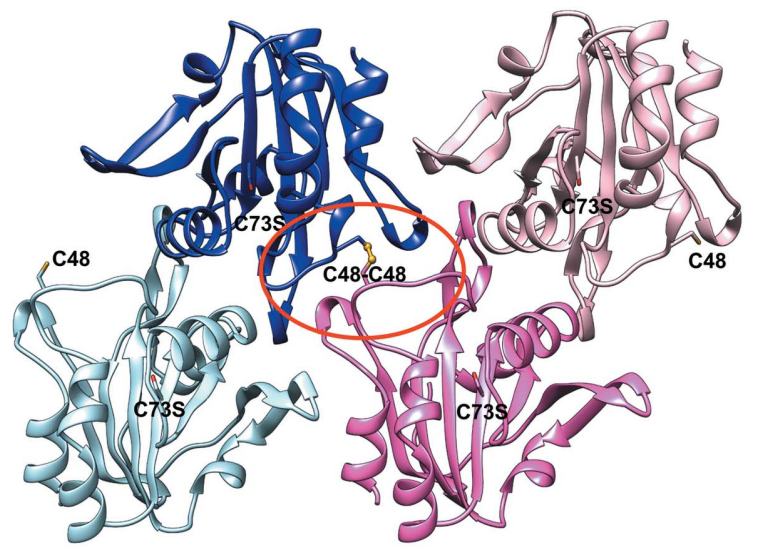

(c)

Figure 1

Overall structure and oligomeric interfaces of $V v \operatorname{Prx} 3$. (a) Ribbon diagram of the reduced Prx3 (C48D/C73S) protomer; $\alpha$-helices, $\beta$-strands and loops are represented in gold, green and grey, respectively. The black arrows indicate the side chains of the mutated residues Cys 48 and Cys 73. (b) Dimeric structure of reduced Prx3 (C48D/C73S) formed by an A-type interface (black circle). The two protomers are coloured differently (green and salmon). The side chains of Cys 48 and Cys 73 are shown in ball-and-stick representation. The black arrows indicate the side chains of the mutated residues (C48D). (c) The asymmetric unit of oxidized Prx3 (C73S) with intact Cys48. Two Cys48 residues from adjacent protomers form a disulfide bond. The crystals of oxidized Prx3 (C73S) were grown without reducing agent. Four protomers are drawn in different colours and the side chains of Cys48 and Ser73 are displayed as ball-and-stick models. The red circle represents the C-type interface. incubated with $10-30 \mu M \mathrm{H}_{2} \mathrm{O}_{2}$ for $30-60 \mathrm{~min}$ at room temperature before loading them onto the column to form the intermolecular disulfide bonds of $V v \operatorname{Prx} 3$ (C73S). Samples were subjected to chromatography, which was performed at a flow rate of $0.2 \mathrm{ml} \mathrm{min}^{-1}$. Several standard preparations were run to calibrate the column: ferritin $(440 \mathrm{kDa})$, aldolase $(158 \mathrm{kDa})$, conalbumin $(75 \mathrm{kDa})$, ovalbumin $(43 \mathrm{kDa})$, carbonic anhydrase $(29 \mathrm{kDa})$ and ribonuclease A (13.7 kDa) (Supplementary Fig. S8). The absorbance at $280 \mathrm{~nm}$ was used to monitor the presence of the proteins.

\subsection{Survival in the presence of nitric oxide (NO)}

The $V$. vulnificus cultures were grown to an $A_{600}$ of 0.5 in LBS broth [LB broth supplemented with $2.0 \%(w / v) \mathrm{NaCl}$ ] at $30^{\circ} \mathrm{C}$ and the cells were harvested by centrifugation at $1500 \mathrm{~g}$ for $7 \mathrm{~min}$ at room temperature. The cell pellets were resuspended in M9 minimal medium supplemented with $0.4 \%(w / v)$ glucose. The bacterial cells $\left[\sim 4 \times 10^{7}\right.$ colony-forming units (CFU)] were exposed to $0.1 \%(w / v) \mathrm{NO} / \mathrm{PPNPs}$ (Nurhasni et al., 2015) for $2 \mathrm{~h}$ and an aliquot was acquired every $20 \mathrm{~min}$. The number of live bacterial cells in the aliquots was determined as the CFU on LBS agar plates. Bacterial strains and plasmids are described in Supplementary Table S1.

\subsection{RNA purification and transcript analysis}

Wild-type $V$. vulnificus cells grown to an $A_{600}$ of 0.5 in LBS broth were exposed to various concentrations of PLGA-PEI nanoparticles (PPNPs) and NO/PPNPs for $20 \mathrm{~min}$ and were harvested to isolate the total RNA. Total RNAs were isolated using an RNeasy Mini kit (Qiagen). For quantitative real-time PCR (qRT-PCR), the concentration of total RNA from the strains was measured using a NanoVue Plus spectrophotometer (GE Healthcare). The cDNA was synthesized from $1 \mu \mathrm{g}$ total RNA using an iScript cDNA-synthesis kit (Bio-Rad). Real-time PCR amplification of cDNA was performed using a Chromo 4 real-time PCR detection system (Bio-Rad) with a pair of specific primers (Supplementary Table S2) as described previously (Jang et al., 2016). The relative expression levels of iscR and prx3 mRNA in the same amount of total RNA were calculated using the 16S rRNA expression level as an internal reference for normalization.

\section{Results}

3.1. Structural determination of reduced Prx3 (C48D/C73S), oxidized Prx3 (C73S) and $\mathrm{H}_{2} \mathrm{O}_{2}$-bound Prx3 (C48D/C73S)

$V v \operatorname{Prx} 3$ contains two cysteine residues: Cys 48 and Cys 73 . Cys48 is the $C_{P}$ residue that is crucial for the function of the protein. However, Cys73 is not involved in protein function because the enzymatic activity of $V v \operatorname{Prx} 3$ (C73S) was similar to that of wild-type $V v \operatorname{Prx} 3$ in the GSH/Grx3/GR system (Lim et al., 2014). To focus on the function of Cys48 and prevent unwanted disulfide-bond formation at Cys73 during SDSPAGE analyses, Cys73 was replaced with a serine residue in this study. To investigate an oxidized structure of Prx3 containing a disulfide bond, the crystal of the oxidized $V v \operatorname{Prx} 3$ 
(C73S) protein was obtained under crystallization conditions without a reducing agent. The crystal structure of $V v \operatorname{Prx} 3$ (C73S) [named oxidized Prx (C73S) in this study] was determined at $1.5 \AA$ resolution in space group $P 2_{1} 2_{1} 2_{1}$ using the molecular replacement method. The resulting structure was refined to an $R_{\text {work }}$ of 0.181 and an $R_{\text {free }}$ of 0.198 (Table 1 ). The final model comprises residues $1-157$ and contains two protein molecules in the asymmetric unit (Table 1). To study the structure of Prx3 in the reduced state, crystals of a $V v \operatorname{Prx} 3$ (C48D/C73S) variant were also obtained. The $\mathrm{C}_{\mathrm{P}}$ Cys48 in $V \nu \operatorname{Prx} 3$ was replaced with a non-oxidizable Asp residue, which could also partly mimic an over-oxidized form $\left(\mathrm{Cys}-\mathrm{SO}_{2} \mathrm{H}\right)$ of $V v \operatorname{Prx} 3$ (Jo et al., 2015). The crystal belonged to a different space group, $P 3_{2} 21$, and the $V v \operatorname{Prx} 3$ (C48D/C73S) structure [named reduced Prx (C48D/C73S) in this study] was determined by the molecular replacement approach. The final model, refined at $1.9 \AA$ resolution $\left(R_{\text {work }}=0.220\right.$ and $R_{\text {free }}=$ 0.258 ), contains one protomer (residues $1-18$ and residues 22157 ) in the asymmetric unit (Table 1). To examine the interactions between $V v \operatorname{Prx} 3$ and peroxides, the $\mathrm{H}_{2} \mathrm{O}_{2}$-bound Prx3 (C48D/C73S) structure was determined at $1.9 \AA$ resolution. A high concentration $(500 \mu M)$ of $\mathrm{H}_{2} \mathrm{O}_{2}$ was incubated with crystals of reduced Prx3 (C48D/C73S), which changed the space group and unit-cell parameters. The resulting structure was refined to an $R_{\text {work }}$ of 0.195 and an $R_{\text {free }}$ of 0.244 . Electrondensity maps were well defined for all 12 protomers in the asymmetric unit (Table 1).

All three crystal structures of $V v \operatorname{Prx} 3$ revealed a protomer exhibiting a compact and spherical structure without a C-terminal extension region, similar to the previously reported 1-Cys Prx AhpE from Mycobacterium tuberculosis (Supplementary Figs. S1 and S2; Li et al., 2005). The $V v \operatorname{Prx} 3$ protomer is formed based on a central five-stranded $\beta$-sheet ( $\beta 5-\beta 4-\beta 3-\beta 8-\beta 9$; Fig. $1 a)$. $\alpha$-Helices $\alpha 2$ and $\alpha 5$ are located on one side of the central $\beta$-sheet, while $\alpha$-helix $\alpha 4$ and the $\beta$-hairpin ( $\beta 1$ and $\beta 2$ ) are on the other side of the central $\beta$-sheet. Strands $\beta 4-\beta 3-\beta 8-\beta 9$ and helices $\alpha 2, \alpha 4$ and $\alpha 5$ comprise the typical Trx fold. In the peripheral region, a $\beta 4$ $\alpha 3-\beta 5$ structural motif is located in the A-type dimeric interface (Figs. $1 a$ and $1 b$ ). $C_{\mathrm{P}}$ Cys48 (or the mutated Asp48) is located at the $\mathrm{N}$-terminus of the long, kinked $\alpha 2$, similar to other Prxs. The mutated Ser73 is buried in the Trx fold region (Fig. 1a). Structural superposition of reduced Prx (C48D/ C73S) on human PrxV (PDB entry 1oc3; sequence identity 52\%; Evrard et al., 2004) revealed high structural similarity, with an r.m.s.d. of $1.46 \AA$ between the $\mathrm{C}^{\alpha}$ positions of 247 matched amino acids (Supplementary Fig. S2).

\subsection{Comparison of structures of $V v \operatorname{Prx} 3$}

All three crystal structures of $V v \operatorname{Prx} 3$ [reduced Prx3 (C48D/ C73S), oxidized Prx3 (C73S) and $\mathrm{H}_{2} \mathrm{O}_{2}$-bound Prx3 (C48D/ C73S)] showed a similar dimeric assembly in the crystals characterized by an A-type dimeric interface, similar to that in AhpE from M. tuberculosis (Supplementary Figs. S1 and S2; Li et al., 2005). In the reduced Prx3 (C48D/C73S) structure the $\mathrm{C}_{\mathrm{p}}$-containing $\alpha 2$ helix at the active site adopted the 'fully folded' or reduced conformation usually observed in Prx structures in the reduced and overoxidized states (Fig. 2; Mizohata et al., 2005; Schröder et al., 2000).

Strikingly, a dimeric interface was found in the oxidized Prx3 (C73S) that was distinct from both the A-type and B-type interfaces (Figs. $1 a$ and $1 b$ ). This dimeric interface was similar to an exceptional oligomeric interface observed in the oxidized structure of $H s \operatorname{Prx} 5$, although this structure contains the disulfide bond between $\mathrm{C}_{\mathrm{P}}$ and $\mathrm{C}_{\mathrm{R}}$ (Smeets et al., 2008), while $V v \operatorname{Prx} 3$ directly forms a dimeric interface through the intermolecular disulfide bond between the $\mathrm{C}_{\mathrm{P}} \mathrm{Cys} 48$ residues. This interface was designated the 'C-type' interface in this study since these oligomeric interfaces was induced by the disulfide bonds.

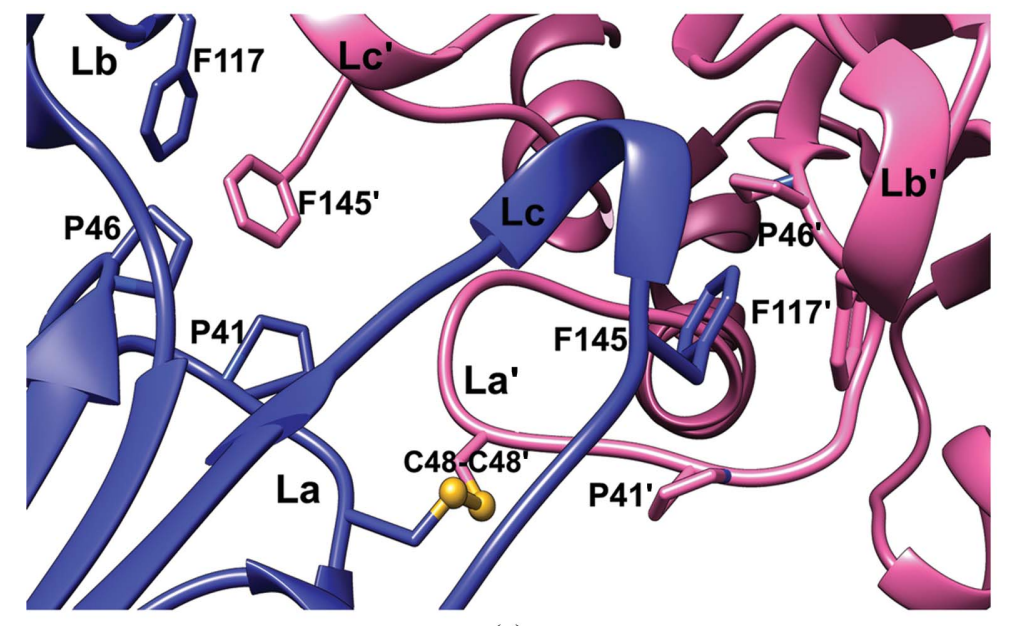

Figure 2 (a)

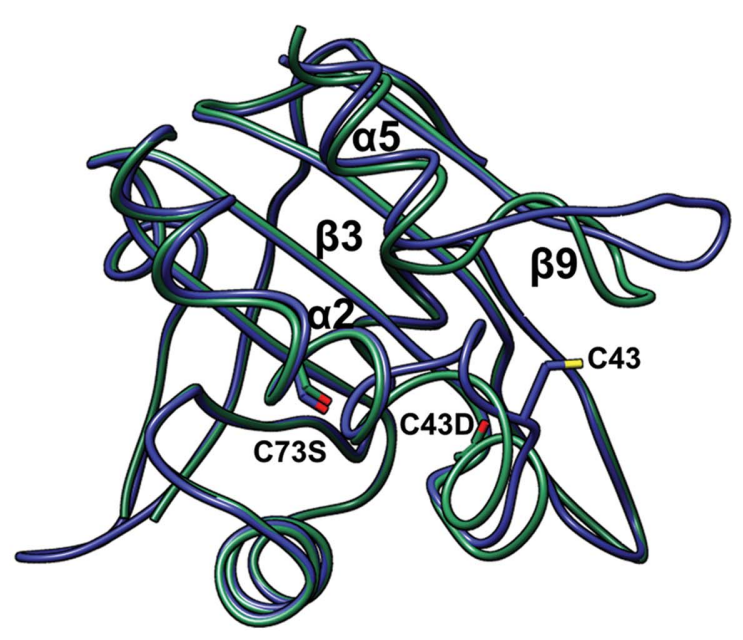

(b)

Structural comparison of $V v \operatorname{Prx} 3$ in reduced and oxidized states. (a) A magnified view focusing on the interactions at the C-type interface (Fig. 1c; red circle) with the intermolecular disulfide bond present between Cys48 residues. The side chains involved in the hydrophobic core are shown in ball-andstick representation. The loops in this interface are labelled $\mathrm{La}, \mathrm{Lb}$ and $\mathrm{Lc}$, indicating the loop connecting $\beta 3$ and $\alpha 2$, the loop connecting $\beta 6$ and $\beta 7$, and the loop connecting $\beta 9$ and $\alpha 5$, respectively. Primes are used in the labels to distinguish the protomers. (b) Structural superposition of $V v$ Prx 3 in the reduced form (green) and the disulfide-bridged (oxidized) form (blue). 
The C-type interface mainly consists of two $\mathrm{C}_{\mathrm{P}}$-containing $\alpha 2$ helices from adjacent protomers (Fig. 1c). Hydrophobic interactions were observed in the C-type interface that appear to further stabilize this dimeric interface. The Phe145 residue in loop $\beta 9-\alpha 5$ of one protomer forms a hydrophobic core with Phe117 in loop $\beta 6-\beta 7$, while Pro41 and Pro46 form a hydrophobic core in the loop connecting $\beta 3$ and $\alpha 2$ of the other molecule (Fig. 2a). Owing to disulfide bonds and hydrophobic interactions, a significant conformational alteration was observed in the active site of helix $\alpha 2$ containing $\mathrm{C}_{\mathrm{P}}$ and nearby loops. In addition, loop $\beta 9-\alpha 5$ moved outwards from the core and loop $\beta 3-\alpha 2$ became ordered in the oxidized Prx 3 (C73S) structure representing the oxidized structure, compared with the reduced Prx3 (C48D/C73S) structure representing the overoxidized or reduced conformation (Fig. $2 b$ ). In $H s$ Prx5, the conformational change of loop $\beta 7-\alpha 6$ corresponding to loop $\beta 9-\alpha 5$ of $V v \operatorname{Prx} 3$ was induced by forming an intramolecular disulfide bond depending on the redox state (Supplementary Fig. S3).

\subsection{Intermolecular disulfide formation of $V v \operatorname{Prx} 3$ reacted} with peroxides, $\mathrm{H}_{2} \mathrm{O}_{2}$ and $t-\mathrm{BOOH}$

To confirm whether the observed disulfide bond in the crystal structure is generated in the solution state, we performed the following biochemical experiment with $\mathrm{H}_{2} \mathrm{O}_{2}$ and $t-\mathrm{BOOH}$, which are known substrates of $V v \operatorname{Prx} 3$ (Dubbs \& Mongkolsuk, 2007; Beckman \& Koppenol, 1996; Lim et al., 2014). Reduced $V v \operatorname{Prx} 3$ (C73S) protein was incubated with $\mathrm{H}_{2} \mathrm{O}_{2}$ or $t$-BOOH and analyzed by SDS-PAGE under nonreducing conditions to observe intermolecular disulfide-bond formation. While boiling the protein sample for SDS-PAGE, free cysteine residues appeared to form nonspecific disulfide bonds. To avoid these nonspecific disulfide bonds, the free thiol-specific alkylating agent iodoacetamide was added to the sample prior to boiling to block free cysteines. We observed that the protein bands were up-shifted to a dimeric size on the SDS-polyacrylamide gels on treatment with $\mathrm{H}_{2} \mathrm{O}_{2}$ or $t$-BOOH (Figs. $3 a$ and $3 b$ ). The protein bands shifted back to a monomeric size when a reducing agent was added to cleave disulfide bonds during boiling. These results indicate that two $V v \operatorname{Prx} 3$ protomers were linked by an intermolecular disulfide bond between two Cys48 residues. Interestingly, the intensities of the dimeric protein bands decreased at higher concentrations of peroxide. Maximum band intensities were shown at $10 \mu \mathrm{M}$ $\mathrm{H}_{2} \mathrm{O}_{2}$ or $t$ - $\mathrm{BOOH}$ (Figs. $3 a$ and $3 b$ ), likely owing to overoxidation of $\mathrm{C}_{\mathrm{P}}$ at high peroxide concentrations (Claiborne $e t$ al., 1999; Rhee et al., 2007). These findings indicate that the intermolecular disulfide bond between $\mathrm{C}_{\mathrm{P}}$ residues is induced by the peroxides $\mathrm{H}_{2} \mathrm{O}_{2}$ and $t$ - $\mathrm{BOOH}$, unlike the prevailing

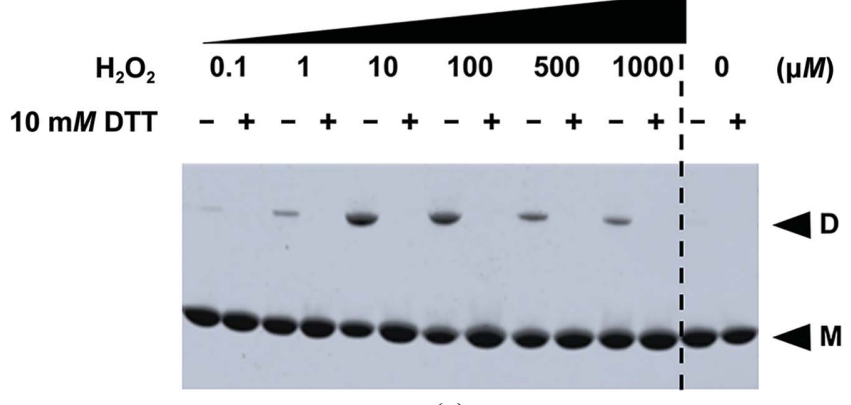

(a)

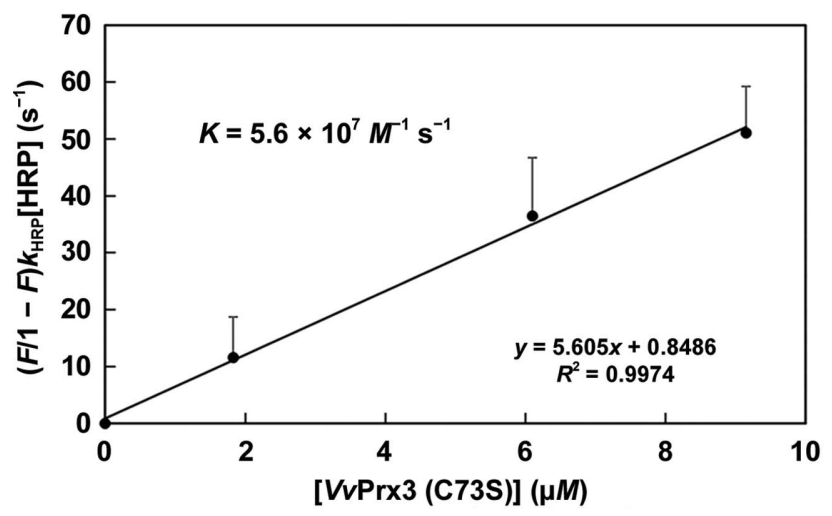

(c)

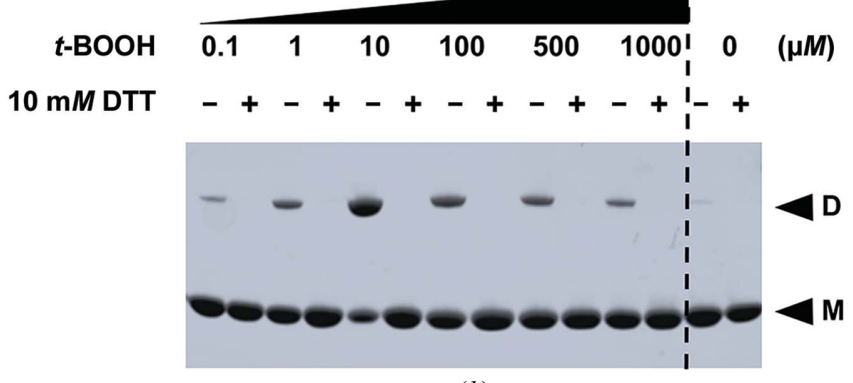

(b)

Figure 3

Intermolecular disulfide-bond formation in $V v \operatorname{Prx} 3(\mathrm{C} 73 \mathrm{~S})$ on treatment with peroxide. Proteins were treated with $\mathrm{H}_{2} \mathrm{O}_{2}(a)$ or tert-butyl hydrogen peroxide $(t-\mathrm{BOOH})(b)$ at the concentrations shown for $30 \mathrm{~min}$ and the reactions were stopped by adding iodoacetamide. Samples were boiled in the presence (+) or absence (-) of $10 \mathrm{~m} M$ DTT for SDS-PAGE analysis. (c) Determination of the second-order reaction rate constant for the reaction of $V v \operatorname{Prx} 3$ and $\mathrm{H}_{2} \mathrm{O}_{2}$ using competition kinetics with HRP. The fitting line was calculated by the least-squares method and the error bars reflect the standard deviation from three independent experiments. (d) Purified $V \nu \operatorname{Prx} 3(\mathrm{C} 73 \mathrm{~S})(70 \mu M)$ was reacted with $50 \mu M \mathrm{H}_{2} \mathrm{O}_{2}$ for the given times and analyzed by SDS-PAGE. At a time of $30 \mathrm{~s}, \sim 30 \mu M$ protein was linked by a disulfide bond as estimated using the density-measuring program ImageJ. The protein band for disulfide bond-containing $V \nu \operatorname{Prx} 3$ (D) and bands that lack a disulfide bond (M) are indicated. 
mechanisms for 1-Cys Prxs via the direct reduction of $\mathrm{C}_{\mathrm{P}}-\mathrm{SOH}$ by Grx or GSH (Noguera-Mazon et al., 2006; Kang et al., 1998; Rhee et al., 2005).

The second-order reaction rate constant $\left(k_{1}\right)$ for $\mathrm{H}_{2} \mathrm{O}_{2}$ consumption by $V v \operatorname{Prx} 3$ was measured by employing competition kinetics with horseradish peroxidase (HRP; Winterbourn \& Peskin, 2016; Cox et al., 2009; Ogusucu et al., 2007). The measured value was $5.6 \times 10^{7} \mathrm{M}^{-1} \mathrm{~s}^{-1}$, which was of the same order as that for human Prx2 (Peskin et al., 2007; Fig. 3c). This finding indicates that $V v \operatorname{Prx} 3$ is as efficient as 2-Cys Prxs. To estimate the reaction rate of dimerization of $V v \operatorname{Prx} 3$, the amount of dimeric $V v \operatorname{Prx} 3$ was measured using the same SDSPAGE method with different incubation times of $V v \operatorname{Prx} 3$ and $\mathrm{H}_{2} \mathrm{O}_{2}$. We observed that almost half of the $V v \operatorname{Prx} 3$ formed an intermolecular disulfide bond within $30 \mathrm{~s}$ (Fig. $3 d$ ), indicating that the reaction velocity for disulfide-bond formation between $V v$ Prx3-SOH and $V v \operatorname{Prx} 3-\mathrm{SH}$ is comparable to a similar reaction with human Prx2 or Prx3 (Gupta \& Carroll, 2014). Taken together, our findings suggest that dimerization of $V v \operatorname{Prx} 3$ could provide a rapid kinetic path to resolving $\mathrm{C}_{\mathrm{P}}$ and is central to the catalysis of the enzyme.

\subsection{Redox-dependent oligomerization of $V v \operatorname{Prx} 3$}

A protein oligomer representing the oxidized state was found in the oxidized Prx3 (C73S) crystals (Fig. 1c). The
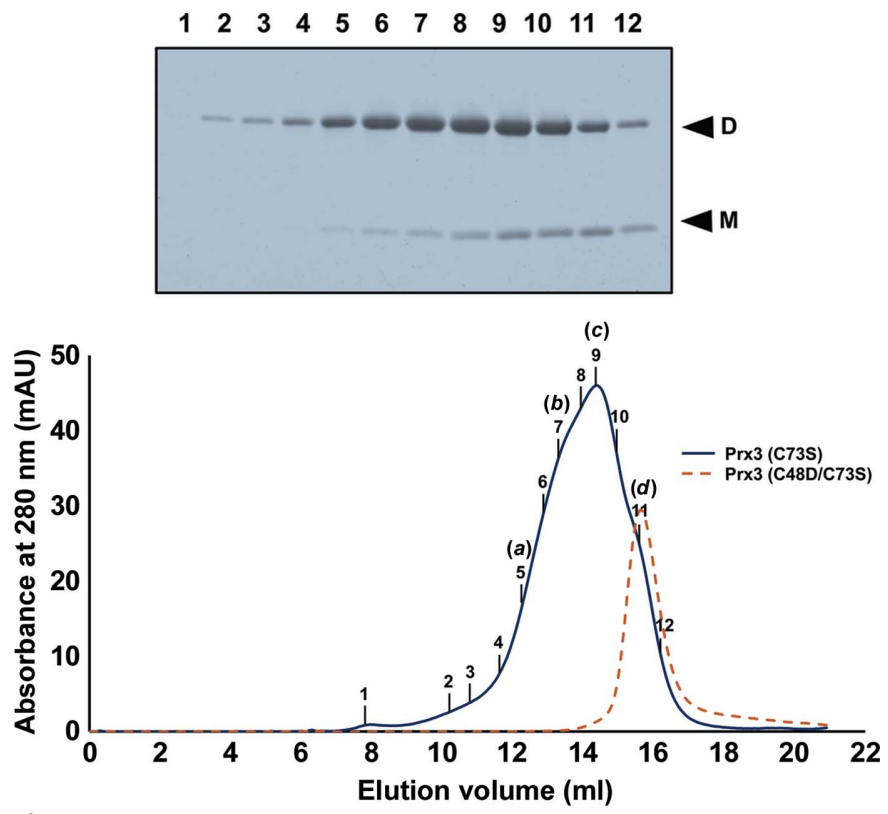

Figure 4

Oligomerization states of $V v \operatorname{Prx} 3$ in solution were analyzed using sizeexclusion chromatography, and fractions were further analyzed by SDSPAGE under nonreducing conditions. The $V v \operatorname{Prx} 3$ (C73S) protein $(33 \mu M)$ was incubated with $\mathrm{H}_{2} \mathrm{O}_{2}(15 \mu M)$ for 60 min before applying size-exclusion chromatography. The result of the native gel electrophoresis is provided in Supplementary Fig. S5. The molecular size was calculated from the standard plot in Supplementary Fig. S8. The molecular sizes of the fractions labelled $(a)-(d)$ correspond to decamer ( $\sim 244 \mathrm{kDa})$, hexamer $(\sim 143 \mathrm{kDa})$, tetramer $(\sim 81 \mathrm{kDa})$ and dimer $(\sim 42 \mathrm{kDa})$, respectively. The protein band of disulfide-bond-containing $V v \operatorname{Prx} 3(\mathrm{D})$ and bands that lack a disulfide bond (M) are indicated. As a control for the non-oxidized sample, $V v \operatorname{Prx} 3$ (C73S/C48S) was analyzed using the same column (shown by a broken line). oligomer is generated in a linear arrangement by alternating connections between the protomers via A-type contacts and C-type contacts (Supplementary Fig. S4). As observed in Fig. 1(c), peroxides induce a disulfide bond between protomers through the C-type interface. The A-type dimer in the reduced state is further linked by the disulfide bond between the $C_{P}$ residues at the $C$-type interface, which can lead to the linear oligomer observed in oxidized Prx3 (C73S) crystals.

To investigate changes in the oligomeric states of $V v \operatorname{Prx} 3$ proteins induced by oxidative stress, the oligomeric state and disulfide-bond formation of $V v \operatorname{Prx} 3$ proteins in the presence/ absence of $\mathrm{H}_{2} \mathrm{O}_{2}$ was analyzed by combining size-exclusion chromatography and SDS-PAGE. In these experiments, two Prx variants were used: C73S and C48D/C73S. To create a disulfide bond between the $\mathrm{C}_{\mathrm{P}}$ residues, $V v \operatorname{Prx} 3$ (C73S) protein was treated with $\mathrm{H}_{2} \mathrm{O}_{2}$ before loading it onto a sizeexclusion chromatograpy column pre-equilibrated with lysis buffer devoid of reducing agent. The elution profile showed a broad early-eluting peak and shoulders before achieving the dimeric size of $V v \operatorname{Prx} 3$, reflecting mixed forms of higher oligomers. Decamers, hexamers, tetramers and dimers were observed on the size-exclusion chromatography column when the molecular sizes were estimated based on the elution volume. The higher oligomeric forms in solution were further confirmed by native gel electrophoresis (Supplementary Fig. $\mathrm{S} 5)$. The higher oligomeric forms contained more $V v \operatorname{Prx} 3$ dimers that are linked by a disulfide bond between two $C_{P}$ residues, as judged by SDS-PAGE under nonreducing conditions (Fig. 4). These results indicate that the higher oligomeric forms of $V v \operatorname{Prx} 3$ were created by noncovalently associated A-type interfaces and disulfide-linked C-type interfaces, as observed in crystals of oxidized Prx3 (C73S).

\section{5. $\mathrm{H}_{2} \mathrm{O}_{2}$ binding site}

Ovoid-shaped electron density indicating $\mathrm{H}_{2} \mathrm{O}_{2}$ was found near Asp48 and the active-site region in the $\mathrm{H}_{2} \mathrm{O}_{2}$-bound $\operatorname{Prx} 3$

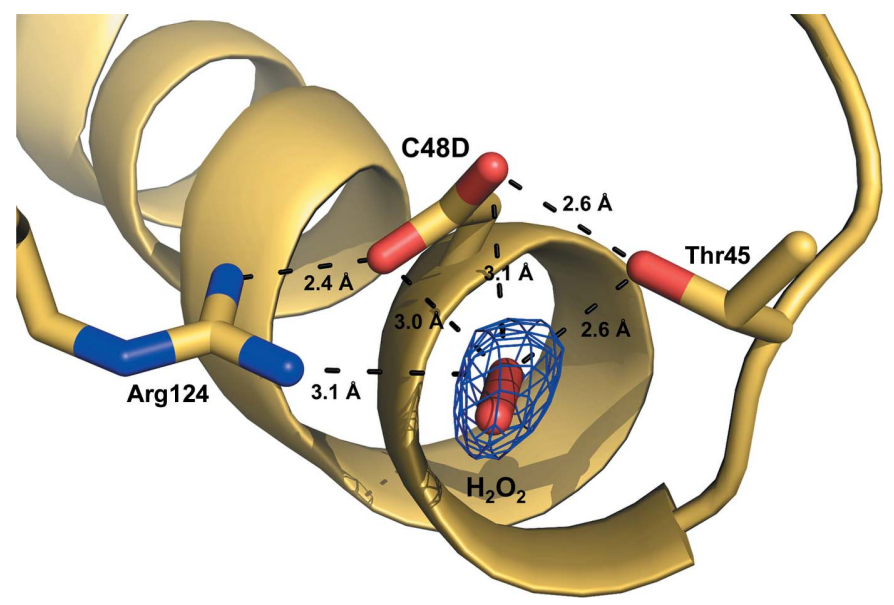

Figure 5

The $\mathrm{H}_{2} \mathrm{O}_{2}$ binding site in $\mathrm{H}_{2} \mathrm{O}_{2}$-bound $\operatorname{Prx} 3(\mathrm{C} 48 \mathrm{D} / \mathrm{C} 73 \mathrm{~S})$ mimics the overoxidized structure. Bound $\mathrm{H}_{2} \mathrm{O}_{2}$ and the residues involved are shown in stick representation at a resolution of $1.9 \AA$. Broken lines indicate the interactions between residues and $\mathrm{H}_{2} \mathrm{O}_{2}$. The ovoid-shaped electron density indicates $\mathrm{H}_{2} \mathrm{O}_{2}$. 
(C48D/C73S) structure (Fig. 5 and Supplementary Fig. S6). The $\mathrm{H}_{2} \mathrm{O}_{2}$ binding site is fully accessible from the solvent since it is exposed to the external medium. The structure is analogous to that of the $\mathrm{H}_{2} \mathrm{O}_{2}$-bound archaeal 2-Cys Prx thioredoxin peroxidase from Aeropyrum pernix K1 (Nakamura et al., 2010), in which the corresponding cysteine residue was overoxidized and shares the $\mathrm{H}_{2} \mathrm{O}_{2}$ binding site (Supplementary Fig. S6d). Thus, it is likely that substrate binding near $\mathrm{C}_{\mathrm{P}}$ is important in the rapid catalysis of $V v \operatorname{Prx} 3$. In Prx structures only one $\mathrm{O}$ atom of $\mathrm{H}_{2} \mathrm{O}_{2}$ near Cys48 (or Asp48 in our structure) makes further interactions with $V v \operatorname{Prx} 3$, while the other $\mathrm{O}$ atom makess no interaction with $\mathrm{H}_{2} \mathrm{O}_{2}$-bound $\mathrm{Prx} 3$ (C48D/C73S) (Fig. 5). Both $\mathrm{O}$ atoms in $\mathrm{H}_{2} \mathrm{O}_{2}$ were extensively involved in polar interactions in OxyR, which can recognize only $\mathrm{H}_{2} \mathrm{O}_{2}$ and not alkyl hydrogen peroxides (Jo et al., 2015). This difference in $\mathrm{H}_{2} \mathrm{O}_{2}$ recognition might result in the different substrate specificities of Prx and OxyR proteins.
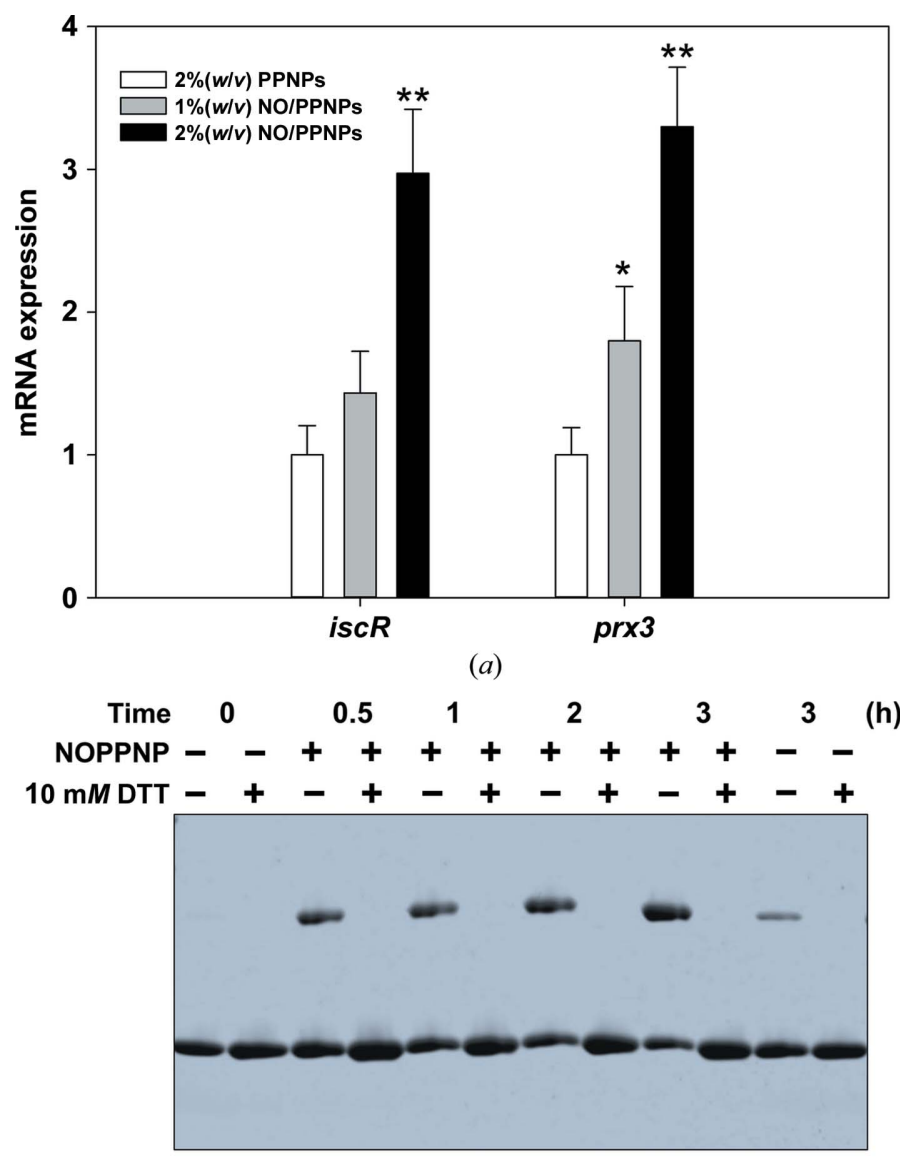

(b)
3.6. NO induces intermolecular disulfide bonds with further oligomerization

Increasing attention has been given to the NO-mediated reactions of host immune systems (Bogdan et al., 2000; Nathan \& Shiloh, 2000). A large amount of NO is synthesized in macrophages or epithelial cells stimulated by pathogens or by substances secreted by pathogens (Beckman \& Koppenol, 1996; Fang, 2004). To investigate the functional relevance of $V v \operatorname{Prx} 3$ and NO, we examined whether $\mathrm{NO}$ can induce the disulfide bonding of $V v \operatorname{Prx} 3$, similar to $\mathrm{H}_{2} \mathrm{O}_{2}$ (Engelman et al., 2013). Although Prxs are known to scavenge reactive nitrogen species such as the peroxinitrite that is rapidly generated by combining NO and superoxide ion (Fang, 2004; Beckman \& Koppenol, 1996; Pfeiffer et al., 1997), direct treatment with NO has not been tested on Prxs. We treated $V$. vulnificus with NOreleasing polymeric nanoparticles (NO/PPNPs), which have recently been developed to allow the sustained release of NO in solution (Nurhasni et al., 2015), and then measured the mRNA levels of prx3 and its known transcription factor iscR. The results showed that the mRNA levels of prx3 and iscR significantly increased, implying that $\mathrm{NO}$ induces $V v \operatorname{Prx} 3$ in V. vulnificus via IscR (Fig. 6a).

We next tested whether NO directly induces disulfide bonds in the $V v \operatorname{Prx} 3$ protein. NO/PPNPs were treated with $V v \operatorname{Prx} 3$ protein, and the disulfide-bond formation of the protein was analyzed by SDS-PAGE and size-exclusion chromatography (Fig. $6 b$ and Supplementary Fig. S7). Compared with airoxidized $V v \operatorname{Prx} 3$ protein, significant protein bands representing the disulfide bond-linked $V v \operatorname{Prx} 3$ increased on the

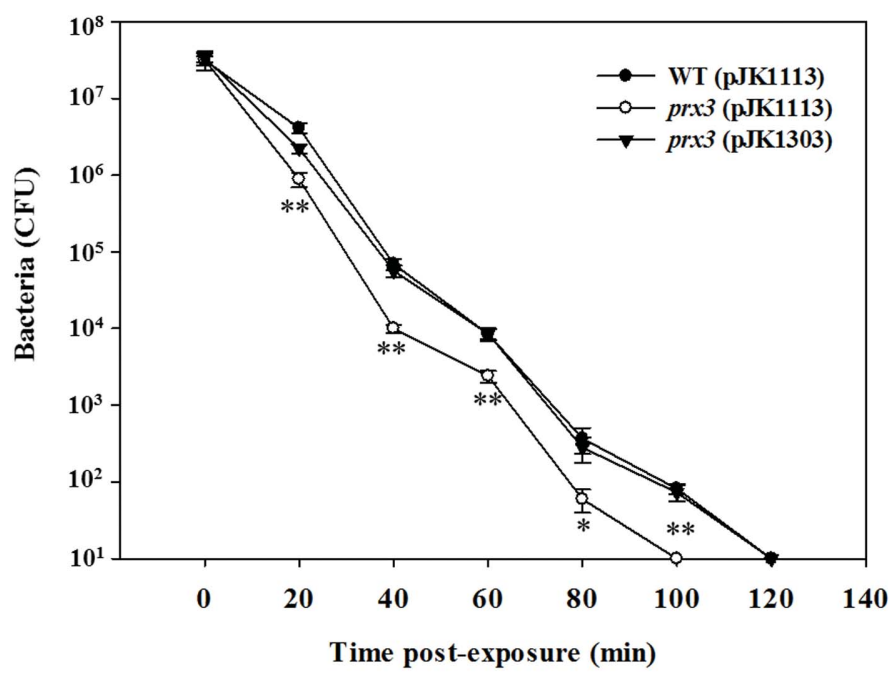

(c)

Figure 6

Effect of NO exposure on Vvprx3 expression and $V v \operatorname{Prx} 3$ protein. (a) Total RNA was isolated from wild-type cells grown aerobically to an $A_{600}$ of 0.5 after exposure to various concentrations of PLGA-PEI nanoparticles (PPNPs) or NO/PPNPs for 20 min. PPNPs were used as blank nanoparticles. The $i s c R$ and $p r x 3$ mRNA levels were determined by qRT-PCR analyses, and the $i s c R$ and $p r x 3$ mRNA levels in the wild type exposed to $0.2 \%(w / v)$ PPNPs were set to 1 . Error bars represent the standard deviation (SD). *, $P<0.05$; **, $P<0.005$. (b) $V v \operatorname{Prx} 3$ (C73S) was incubated with NO/PPNPs for the times shown. A total of $3.3 \mu M \mathrm{NO}$ accumulated in the reaction mixture per hour. The reaction was terminated by adding $2.5 \mathrm{~m} M$ iodoacetamide to prevent nonspecific disulfide bonds. Aliquots were taken from the reaction mixture and loaded onto SDS-PAGE under reducing conditions (DTT +) or nonreducing conditions (DTT -). (c) Survival of $V$. vulnificus strains in the presence of NO stress. Wild-type bacteria (WT) or prx3-deleted bacteria (prx3) were transformed with the empty expression vector pJK1113 or the functional prx3-containing vector pJK1303. Well grown bacterial cells were exposed to NO/PPNPs for the times shown and viable cells were counted as colony-forming units (CFU) on LBS agar plates. Error bars represent the standard deviation (SD). *, $P<0.05 ; * *, P<0.005$. 
SDS-polyacrylamide gel under nonreducing conditions after treatment of the nanoparticles releasing $\sim 1 \mu M$ NO. The NO concentration in solution is much lower than the effective concentration $(\sim 10 \mu M)$ of $\mathrm{H}_{2} \mathrm{O}_{2}$ for $V v \operatorname{Prx} 3$ (Fig. $\left.6 b\right)$. Thus, our results suggest that $V v \operatorname{Prx} 3$ could respond to NO stress through a similar mechanism as for $\mathrm{H}_{2} \mathrm{O}_{2}$ stress.

\section{7. $V v \operatorname{Prx} 3$ supports the survival of $V$. vulnificus under NO stress}

To evaluate the role of $V v \operatorname{Prx} 3$ in resistance to $\mathrm{NO}$ in bacteria, the survival rates of wild-type and $p r x 3$ gene-deleted $V$. vulnificus strains were measured. Compared with the wildtype strain, the $\operatorname{Pr} x 3$ mutant strain exhibited substantially impaired growth in a minimal medium containing NO/PPNPs. When the functional prx3 gene (pJK1303) was added back to the mutant strain, the bacterial survival rate was restored (Fig. 6c). Taken together, our results suggest that $V v \operatorname{Prx} 3$ plays an important role in scavenging NO imposed on the bacteria.

\section{Discussion}

Crystal structures of $V v \operatorname{Prx} 3$, a bacterial 1-Cys Prx, were determined in different redox states in this study. The $\mathrm{H}_{2} \mathrm{O}_{2}$ binding site near the $C_{P}$ residue was also shown. Although structural and sequence similarities to the 1-Cys Prx AhpE from M. tuberculosis were identified, especially in the dimeric assembly with the A-type interface, our structures provide unexpected and important insights into the function and molecular mechanism of Prxs. One striking feature of oxidized Prx3 (C73S) is a dimeric C-type interface with structural changes, which was previously observed in the oxidized form

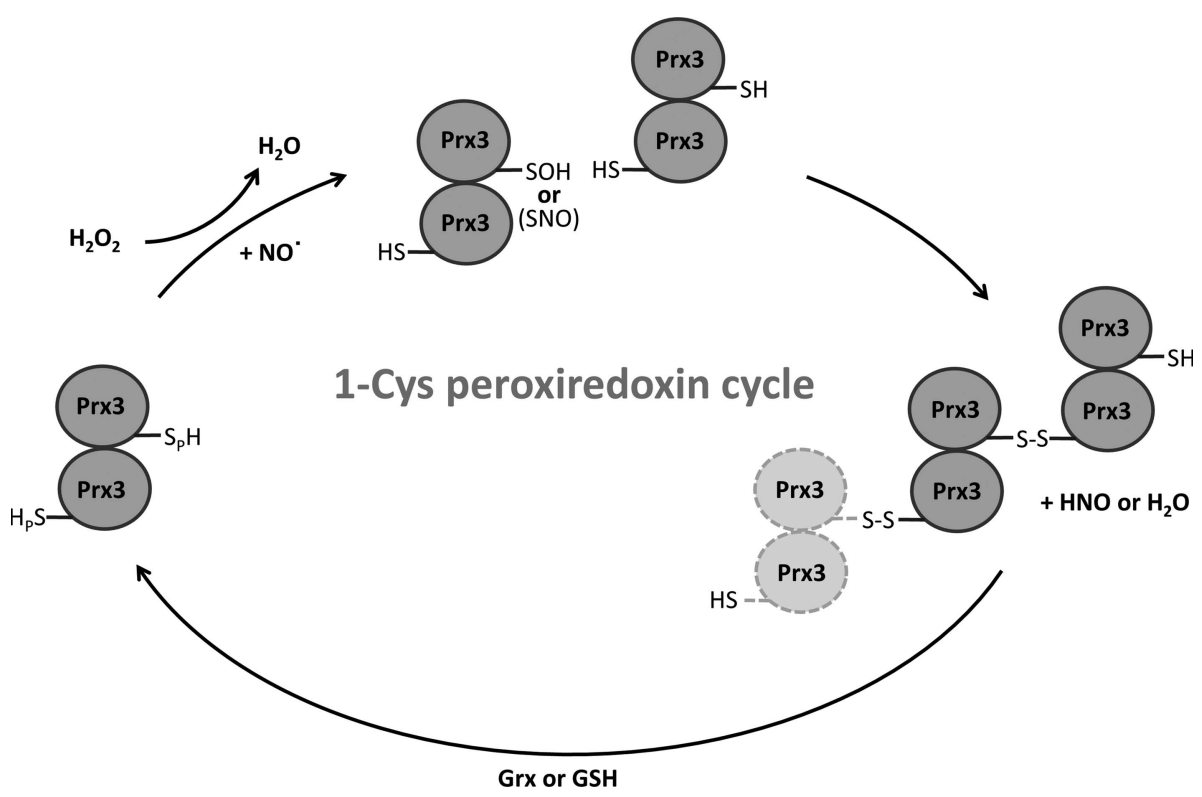

Figure 7

Proposed catalytic cycle of 1-Cys $V v \operatorname{Prx} 3$. Each Prx3 polypeptide is represented by grey circles, with the peroxidatic Cys48 highlighted according to its redox state: sulfhydryl, $-\mathrm{SH}$; sulfenic acid, $-\mathrm{SOH}$; nitrosothiol, $-\mathrm{SNO}$; disulfide, $-\mathrm{S}-\mathrm{S}-$. Potential conformations of additional dimers are indicated by light grey ovals. of $H s$ Prx 5 belonging to the atypical 2-Cys Prx family (Smeets et al., 2008). Since the C-type interface has been observed in two different kinds of Prxs, this oligomeric interface could be shared by many other Prx proteins. This study further observed that protein-protein interaction at the C-type interface was induced by both $\mathrm{NO}$ and peroxides. Owing to the oxidation-dependent C-type interface, $V v \operatorname{Prx} 3$ formed a higher order linear oligomer in response to peroxides and NO. This linear oligomeric structure is distinct from the circular decameric assembly of typical 2-Cys Prxs, which is generated by alternate A-type and B-type interfaces. Since the linear oligomer of $V v \operatorname{Prx} 3$ is generated only in the oxidized state, the redox-dependent oligomerization of $V v \operatorname{Prx} 3$ differs from that of typical 2-Cys Prxs. Interestingly, this linear oligomeric form was also predicted in $H s$ Prx5 (Smeets et al., 2008).

According to the prevailing mechanisms, the $\mathrm{C}_{\mathrm{P}}$ in 1-Cys Prxs is itself oxidized to $\mathrm{C}_{\mathrm{P}}-\mathrm{SOH}$ through attack of the substrate peroxide. $\mathrm{C}_{\mathrm{P}}-\mathrm{SOH}$ is then reduced by the reductase Grx or GSH (Noguera-Mazon et al., 2006; Kang et al., 1998; Rhee et al., 2005). This study presents another pathway for the reduction of $\mathrm{C}_{\mathrm{P}}-\mathrm{SOH}$ in 1-Cys Prxs, which might complement the direct reduction of $\mathrm{C}_{\mathrm{P}}-\mathrm{SOH}$ by Grx or GSH under certain circumstances. In this pathway, the catalytic cysteine residue $\left(\mathrm{C}_{\mathrm{P}}\right)$ in 1-Cys Prx plays a dual role in the catalytic cycle. Not all $V v \operatorname{Prx} 3$ proteins are simultaneously oxidized by $\mathrm{H}_{2} \mathrm{O}_{2}$. Thus, remaining or unreacted $V v \operatorname{Prx} 3$ could act on other $V v \operatorname{Prx} 3 \mathrm{~s}$ with $\mathrm{C}_{\mathrm{P}}-\mathrm{SOH}$. The $\mathrm{C}_{\mathrm{P}}-\mathrm{SOH}$ can be reduced and resolved by free $C_{P}$ in a different dimer of $V v \operatorname{Prx} 3$, in which the free $C_{P}$ acts as a $\mathrm{C}_{\mathrm{R}}$. The complementary structural features at the C-type interface provide specific interactions with $V v \operatorname{Prx} 3$ proteins, facilitating the prompt formation of a disulfide bond between $\mathrm{C}_{\mathrm{P}}-\mathrm{SOH}$ and the free $\mathrm{C}_{\mathrm{P}}$ of $V \nu \operatorname{Prx} 3$ proteins (Fig. $1 c$ ). This reaction could also occur successively, leading to the formation of the linear oligomers observed in the crystal structure (Supplementary Fig. S4). Finally, cellular GSH or Grx that is reduced by GSH reduces the disulfide bond in the oligomer, as proposed previously (Kim et al., 2014). NO can be held in the $\mathrm{H}_{2} \mathrm{O}_{2}$ binding site of the $V \nu \operatorname{Prx} 3$ active site to be readily attacked by $\mathrm{C}_{\mathrm{P}}$. The free $\mathrm{C}_{\mathrm{P}}$ from another $V v \operatorname{Prx} 3$ molecule resolves the resulting nitrosylated cysteine $\left(\mathrm{C}_{\mathrm{P}}-\mathrm{NO}\right)$, as depicted in Fig. 7. Many different members are present in the 1-Cys Prx family. Of these, 1-Cys Prxs from yeast have previously been characterized. As in $V v \operatorname{Prx} 3$, the intermolecular disulfide bond between $C_{P}$ was observed in yeast 1-Cys Prx on an SDS-polyacrylamide gel under nonreducing conditions and predicted a doughnut-like oligomer formation in the oxidized state (Pedrajas et al., 2016). We speculate that yeast 1-Cys Prx might share a catalytic 
cycle with $V \nu \operatorname{Prx} 3$, although further studies are required to elucidate its mechanism.

The pathogenic bacterium $V$. vulnificus can defend against NO stress to increase survival in this harsh host environment. A previous study showed that $V \nu \operatorname{Prx} 3$ is important in the pathogenicity of $V$. vulnificus in mice (Lim et al., 2014). In this study, we observed that NO induced prx3 together with iscR in $V$. vulnificus and that $\mathrm{NO}$ is a substrate of $V v \operatorname{Prx} 3$. These findings suggest that $V \nu \operatorname{Prx} 3$ is important for bacterial survival in NO-challenged environments and might account for the involvement of $V v \operatorname{Prx} 3$ in pathogenicity in the host.

Diverse peroxiredoxins exist in nature and play different roles in the scavenging of toxic radicals. We have proposed a molecular mechanism for bacterial 1-Cys Prxs and a new role in scavenging NO in this study, which may in part account for the pathogenesis of $V$. vulnificus. Our findings expand the understanding of the molecular mechanism of survival of pathogenic bacteria in the host environment by scavenging diverse oxidative and nitrosative stresses.

\section{Acknowledgements}

This study made use of beamlines 5C and 7A at Pohang Light Source, Pohang, Republic of Korea. All authors declare that there is no conflict of interest regarding this study. Author contributions: JA, KKJ, IJ, SHC and $\mathrm{N}-\mathrm{CH}$ designed the research; JA, KKJ, HN and J-WY performed the research; JA, KKJ, IJ, SHC and N-CH analyzed the data; JA, KKJ and N-CH wrote the paper.

\section{Funding information}

This work was supported by the Korea Institute of Planning and Evaluation for Technology in Food, Agriculture, Forestry (IPET) through Agriculture, Food and Rural Affairs Research Center Support Program (to SHC: 710012-03-1-SB110 and NCH: 710012-03-1-HD120), funded by Ministry of Agriculture, Food and Rural Affairs(MAFRA) and by Mid-career Researcher Program Grant 2015R1A2A1A13001654 (to SHC) through the National Research Foundation funded by the Ministry of Science, ICT and Future Planning, Republic of Korea.

\section{References}

Afonine, P. V., Grosse-Kunstleve, R. W., Echols, N., Headd, J. J., Moriarty, N. W., Mustyakimov, M., Terwilliger, T. C., Urzhumtsev, A., Zwart, P. H. \& Adams, P. D. (2012). Acta Cryst. D68, 352-367. Beckman, J. S. \& Koppenol, W. H. (1996). Am. J. Physiol. 271, C1424C1437.

Bogdan, C., Röllinghoff, M. \& Diefenbach, A. (2000). Curr. Opin. Immunol. 12, 64-76.

Bryk, R., Griffin, P. \& Nathan, C. (2000). Nature (London), 407, 211215.

Cabiscol, E., Tamarit, J. \& Ros, J. (2000). Int. Microbiol. 3, 3-8.

Chae, H. Z., Kang, S. W. \& Rhee, S. G. (1999). Methods Enzymol. 300, 219-226.

Claiborne, A., Yeh, J. I., Mallett, T. C., Luba, J., Crane, E. J. III, Charrier, V. \& Parsonage, D. (1999). Biochemistry, 38, 1540715416.
Cox, A. G., Peskin, A. V., Paton, L. N., Winterbourn, C. C. \& Hampton, M. B. (2009). Biochemistry, 48, 6495-6501.

Dubbs, J. M. \& Mongkolsuk, S. (2007). Subcell. Biochem. 44, 143-193.

Echalier, A., Trivelli, X., Corbier, C., Rouhier, N., Walker, O., Tsan, P., Jacquot, J.-P., Aubry, A., Krimm, I. \& Lancelin, J.-M. (2005). Biochemistry, 44, 1755-1767.

Engelman, R., Weisman-Shomer, P., Ziv, T., Xu, J., Arnér, E. S. \& Benhar, M. (2013). J. Biol. Chem. 288, 11312-11324.

Evrard, C., Capron, A., Marchand, C., Clippe, A., Wattiez, R., Soumillion, P., Knoops, B. \& Declercq, J.-P. (2004). J. Mol. Biol. 337, 1079-1090.

Fang, F. C. (2004). Nat. Rev. Microbiol. 2, 820-832.

Gupta, V. \& Carroll, K. S. (2014). Biochim. Biophys. Acta, 1840, $847-$ 875.

Hall, A., Karplus, P. A. \& Poole, L. B. (2009). FEBS J. 276, 2469 2477.

Hall, A., Nelson, K., Poole, L. B. \& Karplus, P. A. (2011). Antioxid. Redox Signal. 15, 795-815.

Halliwell, B. (2006). Plant Physiol. 141, 312-322.

Ho, S. N., Hunt, H. D., Horton, R. M., Pullen, J. K. \& Pease, L. R. (1989). Gene, 77, 51-59.

Horseman, M. A. \& Surani, S. (2011). Int. J. Infect. Dis. 15, e157-e166.

Jang, K. K., Gil, S. Y., Lim, J. G. \& Choi, S. H. (2016). J. Biol. Chem. 291, 5774-5787.

Jo, I., Chung, I.-Y., Bae, H.-W., Kim, J.-S., Song, S., Cho, Y.-H. \& Ha, N.-C. (2015). Proc. Natl Acad. Sci. USA, 112, 6443-6448.

Kang, S. W., Baines, I. C. \& Rhee, S. G. (1998). J. Biol. Chem. 273, 6303-6311.

Kim, S., Bang, Y.-J., Kim, D., Lim, J. G., Oh, M. H. \& Choi, S. H. (2014). Mol. Microbiol. 93, 992-1009.

Li, S., Peterson, N. A., Kim, M.-Y., Kim, C.-Y., Hung, L.-W., Yu, M., Lekin, T., Segelke, B. W., Lott, J. S. \& Baker, E. N. (2005). J. Mol. Biol. 346, 1035-1046.

Lim, J. G., Bang, Y.-J. \& Choi, S. H. (2014). J. Biol. Chem. 289, $36263-$ 36274.

Mizohata, E., Sakai, H., Fusatomi, E., Terada, T., Murayama, K., Shirouzu, M. \& Yokoyama, S. (2005). J. Mol. Biol. 354, 317-329.

Nakamura, T., Kado, Y., Yamaguchi, T., Matsumura, H., Ishikawa, K. \& Inoue, T. (2010). J. Biochem. 147, 109-115.

Nakamura, T., Yamamoto, T., Inoue, T., Matsumura, H., Kobayashi, A., Hagihara, Y., Uegaki, K., Ataka, M., Kai, Y. \& Ishikawa, K. (2006). Proteins, 62, 822-826.

Nathan, C. \& Shiloh, M. U. (2000). Proc. Natl Acad. Sci. USA, 97, 8841-8848.

Noguera-Mazon, V., Lemoine, J., Walker, O., Rouhier, N., Salvador, A., Jacquot, J.-P., Lancelin, J.-M. \& Krimm, I. (2006). J. Biol. Chem. 281, 31736-31742.

Nurhasni, H., Cao, J., Choi, M., Kim, I., Lee, B. L., Jung, Y. \& Yoo, J.-W. (2015). Int. J. Nanomedicine, 10, 3065-3080.

Ogusucu, R., Rettori, D., Munhoz, D. C., Soares Netto, L. E. \& Augusto, O. (2007). Free Radical Biol. Med. 42, 326-334.

Oliver, J. D. (2005). Epidemiol. Infect. 133, 383-391.

Otwinowski, Z. \& Minor, W. (1997). Methods Enzymol. 276, 307-326.

Parsonage, D., Youngblood, D. S., Sarma, G. N., Wood, Z. A., Karplus, P. A. \& Poole, L. B. (2005). Biochemistry, 44, 10583-10592.

Pedrajas, J. R., McDonagh, B., Hernandez-Torres, F., MirandaVizuete, A., Gonzalez-Ojeda, R., Martinez-Galisteo, E., Padilla, C. A. \& Barcena, J. A. (2016). Antioxid. Redox Signal. 24, 115-128.

Peskin, A. V., Low, F. M., Paton, L. N., Maghzal, G. J., Hampton, M. B. \& Winterbourn, C. C. (2007). J. Biol. Chem. 282, 11885-11892.

Pfeiffer, S., Gorren, A. C., Schmidt, K., Werner, E. R., Hansert, B., Bohle, D. S. \& Mayer, B. (1997). J. Biol. Chem. 272, 3465-3470.

Rhee, S. G., Chae, H. Z. \& Kim, K. (2005). Free Radical Biol. Med. 38 , 1543-1552.

Rhee, S. G., Jeong, W., Chang, T. S. \& Woo, H. A. (2007). Kidney Int. Suppl., pp. S3-S8.

Schröder, E., Littlechild, J. A., Lebedev, A. A., Errington, N., Vagin, A. A. \& Isupov, M. N. (2000). Structure, 8, 605-615. 
Seo, M. S., Kang, S. W., Kim, K., Baines, I. C., Lee, T. H. \& Rhee, S. G. (2000). J. Biol. Chem. 275, 20346-20354.

Smeets, A., Marchand, C., Linard, D., Knoops, B. \& Declercq, J.-P. (2008). Arch. Biochem. Biophys. 477, 98-104.

Temple, M. D., Perrone, G. G. \& Dawes, I. W. (2005). Trends Cell Biol. 15, 319-326.

Winn, M. D. et al. (2011). Acta Cryst. D67, 235-242.
Winterbourn, C. C. \& Peskin, A. V. (2016). Mol. Cells, 39, 26-30.

Wong, C.-M., Zhou, Y., Ng, R. W. M., Kung, H.-F. \& Jin, D.-Y. (2002). J. Biol. Chem. 277, 5385-5394.

Wood, Z. A., Poole, L. B., Hantgan, R. R. \& Karplus, P. A. (2002). Biochemistry, 41, 5493-5504.

Wood, Z. A., Schröder, E., Robin Harris, J. \& Poole, L. B. (2003). Trends Biochem. Sci. 28, 32-40. 